\title{
Botany
}

American Journal of Botany 99(7): 1197-1206. 2012.

\section{Plasticity in bundle Sheath extensions OF HETEROBARIC LEAVES ${ }^{1}$}

\author{
Douglas J. Lynch ${ }^{2,3,5,8}$, Francesca A. McInerney ${ }^{4}$, Lenny L.R. Kouwenberg ${ }^{6,7}$, \\ and Miquel A. GonZAlez-Meler ${ }^{5}$
}

\begin{abstract}
${ }^{2}$ Northwestern University, Program in Plant Biology and Conservation, 2205 Tech Drive, Evanston, Illinois 60208 USA; ${ }^{3}$ Chicago Botanic Garden, 1000 Lake Cook Road, Glencoe, Illinois 60022 USA; ${ }^{4}$ Northwestern University, Department of Earth and Planetary Sciences, 1850 Campus Drive, Evanston, Illinois 60208 USA; ${ }^{5}$ Department of Biological Sciences, University of Illinois at Chicago (UIC), Chicago, Illinois 60607 USA; ${ }^{6}$ Field Museum of Natural History, Department of Geology, 1400 S. Lake Shore Drive, Chicago, Illinois 60605 USA; and ${ }^{7}$ University of California at Berkeley, Department of Integrative Biology, VLSB 3060, Berkeley, California 94720 USA
\end{abstract}

- Premise of the study: Leaf venation is linked to physiological performance, playing a critical role in ecosystem function. Despite the importance of leaf venation, associated bundle sheath extensions (BSEs) remain largely unstudied. Here, we quantify plasticity in the spacing of BSEs over irradiance and precipitation gradients. Because physiological function(s) of BSEs remain uncertain, we additionally explored a link between BSEs and water use efficiency (WUE).

- Methods: We sampled leaves of heterobaric trees along intracrown irradiance gradients in natural environments and growth chambers and correlated BSE spacing to incident irradiance. Additionally, we sampled leaves along a precipitation gradient and correlated BSE spacing to precipitation and bulk $\delta^{13} \mathrm{C}$, a proxy for intrinsic WUE. BSE spacing was quantified using a novel semiautomatic method on fresh leaf tissue.

- Key results: With increased irradiance or decreased precipitation, Liquidambar styraciflua decreased BSE spacing, while Acer saccharum showed little variation in BSE spacing. Two additional species, Quercus robur and Platanus occidentalis, decreased BSE spacing with increased irradiance in growth chambers. BSE spacing correlated with bulk $\delta^{13} \mathrm{C}$, a proxy for WUE in L. styraciflua, Q. robur, and P. occidentalis leaves but not in leaves of A. saccharum.

- Conclusions: We demonstrated that BSE spacing is plastic with respect to irradiance or precipitation and independent from veins, indicating BSE involvement in leaf adaptation to a microenvironment. Plasticity in BSE spacing was correlated with WUE only in some species, not supporting a function in water relations. We discuss a possible link between BSE plasticity and life history, particularly canopy position.

Key words: Acer saccharum; bulk $\delta^{13} \mathrm{C}$; bundle sheath extension; heterobaric; Liquidambar styraciflua; plasticity; water use efficiency.

Plant traits are an important component of ecosystem fluxes that dominate the exchange of water and $\mathrm{CO}_{2}$ between the atmosphere and the terrestrial biosphere. The evolution of vascular tissue networks was a critical trait for early plant evolution (Niklas, 1997), and dramatic increases in vein density greatly improved photosynthetic capacity during angiosperm evolution (Brodribb and Feild, 2010) Because plant branching in general

\footnotetext{
${ }^{1}$ Manuscript received 2 November 2011; revision accepted 12 June 2012. The authors thank all the managers at the arboreta and botanical gardens where sampling was performed: Chicago Botanic Garden (B. Tankersley), Bruce Park (staff) Midland Lutheran College Arboretum (G. Carlson), The Brenton Arboretum (A. Schmitz), Missouri Botanic Garden (staff), Memphis Botanic Garden (K. McLane), Hilltop Arboretum (staff), and $\mathrm{K}$. Maher (for preparing cleared leaf samples and images of the growth chamber material) and C. Looy. Thanks to J. Shi and K. Shedd for their work in grinding and weighing leaves for carbon isotope analysis and to the NU and UIC personnel assisting with isotopic analyses. The authors thank two anonymous reviewers for valuable contributions that greatly improved this manuscript. Funding for this research was provided by the Northwestern University Award in Plant Biology and Conservation.

${ }^{8}$ Author for correspondence (e-mail: dlynch3@ uic.edu), present address: Department of Biological Sciences, University of Illinois at Chicago (UIC), 845 W. Taylor St. (M/C 066) SES Building, Chicago, IL 60607 USA; phone: 773-614-2488
}

doi:10.3732/ajb.1100525 and leaf venation structure in particular has been linked to physiological performance (Blonder et al., 2011; Roth-Nebelsick et al., 2001), leaf anatomical traits are important to understand ecosystem dynamics and function (Lavorel et al., 2011; Moorcroft et al., 2001). Venation patterns at the leaf level are known to respond to environmental factors (Ellis et al., 2009), further emphasizing the functional importance of leaf vein anatomical traits in plants. Vein anatomy differs substantially between species (Roth-Nebelsick et al., 2001). One potentially significant difference between species is maintenance of bundle sheath extensions, resulting in heterobaric leaves. Despite the recognized physiological importance of plastic leaf venation patterns, the degree of plasticity and functional advantages of a plastic leaf heterobaric trait have not been described.

Bundle sheath extensions (BSE) surround bundle sheath cells on some veins and extend to the epidermis on both sides of the leaf (Wylie, 1952). Leaves with BSEs on at least some of their veins are known as heterobaric, while homobaric leaves lack BSEs entirely (Esau, 1953). Some heterobaric species maintain BSEs strictly on primary veins, while others include secondary and/or tertiary veins (Wylie, 1952). A major consequence of BSEs is the division of the leaf into compartments with potentially multiple advantages (described below). The surface area of these internal leaf compartments is determined by the distance between BSEs and varies between species. Variation in BSE spacing (i.e., the average distance between BSEs in a leaf) 
on the same individual was found in ca. 10 species (in one unreplicated study), with shade leaves maintaining larger BSE spacing compared to sun leaves (Wylie, 1951). However, these potentially BSE plastic responses have not been characterized in terms of occurrence or magnitude in relation to environmental variables. Understanding the environmental drivers for the plastic response within individuals, within species and among species with different life histories will ultimately provide insights into the physiological function of BSEs.

Little is currently known about the functionality of BSEs although many potential roles have been hypothesized. As heterobaric leaves tend to be thinner and easily damaged, BSEs may protect the leaf from wind damage by providing mechanical structural support (Lawson and Morison, 2006). Alternatively, compartmentalization provided by BSEs may assist in preventing the spread of disease (Lawson and Morison, 2006). As BSE presence tends to inversely correlate with vein density, BSEs may provide additional water carrying capacity (Leegood, 2008). While none of the aforementioned hypotheses are supported with experimental evidence, BSEs are known to affect the gas exchange characteristics of plant leaves (see Gonzalez-Meler and Taneva, 2005 for examples). Because BSEs can reduce hydraulic resistance between the bundle sheath vessels and the epidermis including stomata (Buckley et al., 2011), some studies have explored the hypothesis that BSEs affect assimilation rates and water use efficiency (WUE).

The presence of BSEs could affect water use efficiency through a number of different means. The compartmentalization of a leaf caused by BSEs could enable spatial heterogeneity in gas exchange by managing stomata differently in different leaf patch compartments (Terashima, 1992). The speed of stomatal response may be influenced by the presence of BSEs by equilibrating xylem and epidermal water potentials (Buckley et al., 2011), thereby reducing the impact of nonuniform photosynthesis on WUE (Buckley et al., 2011, Terashima, 1992). A second potential means by which BSEs may enhance WUE involves the transparent nature of BSEs. Bundle sheath extensions are nonphotosynthetic and transparent to visible light, diffusing light energy into the internal mesophyll layers (Nikolopoulos et al., 2002). As a result, heterobaric leaves demonstrated increased assimilation rates per unit of leaf area likely due to this increased absorption of light energy (Nikolopoulos et al., 2002). This increase in assimilation can indirectly result in enhanced WUE. However, BSE prevents lateral diffusion of $\mathrm{CO}_{2}$ within the leaf, and the internal diffusion of $\mathrm{CO}_{2}$ has been experimentally shown to increase assimilation rates, and potentially WUE, in homobaric leaves (i.e., lacking BSEs), particularly under patchy irradiance conditions (Morison et al., 2007; Pieruschka et al., 2005, 2006, 2008) with some exceptions (e.g., Morison and Lawson, 2007). While several potential mechanisms link the maintenance of BSEs to WUE, experimental evidence to support them is lacking. If BSE spacing is directly related to improvements in gas exchange, plants may benefit from a plastic expression of BSE spacing under conditions known to affect WUE.

To characterize plasticity in BSE spacing in natural environments and explore a potential role of BSEs on WUE, we examined variation in BSE spacing along environmental gradients in irradiance and precipitation, factors known to affect photosynthesis and WUE (Farquhar et al., 1982; Dawson et al., 2002; Flexas et al., 2008). Using a novel method to measure BSE spacing on fresh leaf tissue, we examined plasticity in BSE spacing in Liquidambar styraciflua L. (canopy species) and Acer saccharum Marsh. (shade-tolerant species). Leaves were sampled from around the canopy of individual trees providing a range of irradiance through self-shading. Leaves were also sampled from trees grown along a precipitation gradient across the central USA. Additional data on BSE plasticity were obtained from two canopy species (Quercus robur L. and Platanus occidentalis L.) grown in controlled environment chambers under different irradiance treatments. Variations in BSE spacing across these gradients and treatments were examined in relation to bulk leaf $\delta^{13} \mathrm{C}$, a long-term proxy for WUE (Farquhar et al., 1982, Seibt et al., 2008). We also examined potential intraleaf heterogeneity in bulk leaf $\delta^{13} \mathrm{C}$. Last, we discuss a potential link between life history and functionality of bundle sheath extensions under conditions known to affect leaf gas exchange characteristics.

\section{MATERIALS AND METHODS}

Irradiance gradient within tree crown sampling-Three individuals of Liquidambar styraciflua L. (Hamamelidaceae) and four of Acer saccharum Marsh. (Aceraceae) were sampled at the Chicago Botanic Garden in Glencoe, Illinois, USA. All selected individuals were solitary with a minimum diameter at breast height of $15 \mathrm{~cm}$. The sampling method followed the well-established "around tree method" (Lockheart et al., 1997), in which leaves were collected from the four cardinal and four intercardinal directions. From each of the eight directions, a full-sun leaf on the crown edge, a partial-shade leaf midway between trunk and crown edge, and a full-shade leaf near the trunk were sampled, totaling 24 leaves per individual. Sampled leaves were taken from branches at the lowest point of the crown of the tree at ca. $2 \mathrm{~m}$ from the ground to maximize the effect of the directionality of the leaf as well as to control for physiological differences related to leaf height (Zwieniecki et al., 2004). Sampling occurred on sunny days free of cloud cover in June and July 2008. On the morning of sampling, each leaf to be sampled was marked and irradiance at each leaf recorded with a Technika 840020 light meter (Technika, Scottsdale, Arizona, USA) every hour from 1000 hours to at least 1400 hours. Irradiance used in analysis is the mean intensity measured between 1000 hours and 1400 hours at each leaf. While this methodology may not accurately capture seasonal variation in irradiance, it does provide a metric with which to compare received irradiance in leaves for this study. Leaves were removed at the petiole base and temporarily stored between moist paper towels and taken to the laboratory for further analysis.

Precipitation gradient sampling-Specimens of L. styraciflua and A. saccharum were sampled along a geographic precipitation gradient. Leaf sampling was performed at seven arboreta and botanical garden locations with large variation in precipitation (Table 1). Mean annual precipitation at collection sites ranged from $639 \mathrm{~mm} \cdot \mathrm{yr}^{-1}$ to $1617 \mathrm{~mm} \cdot \mathrm{yr}^{-1}$ as measured by the nearest NCDC weather station (PRISM Climate Group, 2009). Specific sampling sites were chosen at arboreta and botanical gardens where species and cultivars are well identified and trees received no additional water or fertilizer after establishment. All selected trees were solitary. Because the use of a single cultivar along the entire transect was not possible, a range of cultivars was selected at each site to maximize species trend and reduce confounding genotypic effects. Three or four individuals of each species at each site were sampled, with the exception of one site for each species (Table 1).

Two sets of leaves were sampled from each tree: south leaves on the crown edge ("sun") and north leaves near the trunk ("shade") to maximize the potential within canopy light gradient (Sack et al., 2003). All leaves were sampled at the bottom of the crown, ca. $2 \mathrm{~m}$ from the ground. Each leaf was immediately placed between moist paper towels, placed in a ziplocking storage bag in a cooler with ice, and brought to the laboratory for analysis.

Growth chamber experiments-Saplings of Platanus occidentalis and Quercus robur were grown from April 2008 to July 2008 in two Conviron E8 growth chambers at the Field Museum of Natural History, Chicago, Illinois, USA. A "low light" treatment chamber maintained irradiance levels of 20-40 $\mu \mathrm{mol} \cdot \mathrm{m}^{2} \cdot \mathrm{s}^{-1}$, and a "high light" treatment maintained irradiance of 200-300 $\mu \mathrm{mol} \cdot \mathrm{m}^{2} \cdot \mathrm{s}^{-1}$. Plants were grown in 6-L containers filled with a mixture of peat moss, perlite, and sand $(2: 1: 1)$ and watered twice a week with an automated sprinkler system. Chambers were environmentally controlled for temperature, 
TABLE 1. Sampling locations for the precipitation gradient section.

\begin{tabular}{lcccccc}
\hline \hline Site name & Latitude & Longitude & $\begin{array}{c}\text { A. saccharum } \\
\text { individuals }\end{array}$ & $\begin{array}{c}\text { L. styraciflua } \\
\text { individuals }\end{array}$ & $\begin{array}{c}\text { Mean annual precipitation } \\
\text { (mm.yr }{ }^{-1} \text { ) }\end{array}$ & NCDC weather station \\
\hline Bruce Park/Gilman Park & 42.464 & -97.914 & 4 & 1 & 639 & Randolph 6S \\
Midland Lutheran College Arboretum & 41.438 & -96.488 & 4 & 3 & 764 & Fremont \\
The Brenton Arboretum & 41.661 & -93.991 & 3 & 4 & 819 & Perry \\
Chicago Botanic Garden & 42.1467 & -87.791 & 4 & 3 & Chicago Botanic Garden \\
Missouri Botanic Garden & 38.611 & -90.259 & 4 & 3 & 994 & St. Louis Lambert Airport \\
Memphis Botanic Garden/Overton Park & 35.108 & -89.918 & 4 & 4 & 1401 & Memphis Airport \\
Hilltop Arboretum Ruth Park & 30.444 & -91.106 & 1 & 4 & 1617 & Baton Rouge Ryan Airport \\
Totals & & & $\mathbf{2 4}$ & $\mathbf{2 2}$ & &
\end{tabular}

Notes: Precipitation data are mean annual precipitation from the closest NCDC weather station. Latitude and longitude are approximate locations and are in WGS84 decimal degrees.

irradiance level, and photoperiod, which were programmed to mimic a typical 24-h cycle during the growth season in northern California. $\mathrm{CO}_{2}$ levels were monitored constantly and were stable at $\sim 500 \mu \mathrm{L} \cdot \mathrm{L}^{-1}$ in both chambers. Relative humidity was kept at ca. 70-85\%. For BSE spacing analysis, four leaves per species were sampled from each chamber and placed in moist paper towels in a ziplocking bag and brought to the laboratory for analysis. For vein spacing analysis, five leaves per species were sampled from each chamber. Leaves sampled for both BSE spacing and vein analysis represent the complete range of heights on the stems $(68-110 \mathrm{~cm})$.

Bundle sheath extension spacing analysis-BSE spacing was analyzed by viewing fresh leaf tissue under a compound microscope with transmitted light. For each collected leaf, six $1-\mathrm{cm}^{2}$ digital images were captured under $10 \times$ magnification using a Leica DFC280 digital camera connected to a Zeiss Discovery V.12 compound microscope at the Chicago Botanic Garden laboratory. Areas selected for analysis were away from both the midrib and the margins and were kept constant between leaves (Wylie, 1951). BSEs appear as white lines in microscopic images due to their transparency since they lack chlorophyll (Fig. 1A-C). Previous authors have used this property to quantify BSEs (Nikolopoulos et al., 2002; Kenzo et al., 2007), and a comparison of fresh tissue showing BSEs only (Fig. 1C) and cleared tissue showing all veins (Fig. 1D) demonstrates the efficacy of this method. Bundle sheath extension spacing analysis and calculations were performed on the digital images using a custom made plugin/algorithm by the main author for ImageJ freeware (Rasband, 1997-2008; plugin available upon request from D. Lynch). Images were first cropped to $0.75 \mathrm{~cm}^{2}$ and converted to grayscale. Three transects of $0.75 \mathrm{~cm}$ in length were placed on each image in randomly selected locations by the algorithm. The grayscale value of each pixel along each transect was analyzed, and each intersection of the transect line and white BSE tissue (i.e., high grayscale value) was counted by a peak-detect algorithm. A manual verification of each detected peak removed errors caused by occasional poor image quality in some of the sections. The number of intersections along the $0.75-\mathrm{cm}$ transect was then converted to average distance between BSE. This metric of measuring BSE is used throughout and referred to as BSE spacing. Vein spacing measured on transects correlates well with vein length per area (Uhl and Mosbrugger, 1999), and it is assumed this is valid for BSEs as well. Results from the six sections per leaf were averaged to determine BSE spacing for the leaf. For each leaf, 18 transects at $0.75 \mathrm{~cm}$ per transect were analyzed for a total of $13.5 \mathrm{~cm}$ per leaf.

For vein spacing analysis, $\sim 1 \mathrm{~cm}^{2}$ was excised just off the midvein, halfway between the apex and base of the leaf. The leaf sections were cleared using the protocol described in Ellis et al., (2009) but with 5\% KOH and 4\% household bleach, and safranin was used for staining. The cleared leaf sections were mounted on slides, and digital images were then obtained at 50× magnification using a Nikon DS-L2 imaging system mounted on a Leica DM2500 microscope. Vein spacing was then measured using the same method previously described for BSE spacing.

Bulk leaf $\delta^{13}$ C analysis-Carbon isotope ratios for bulk tissues were measured on all leaves sampled on the precipitation gradient. After BSE spacing analysis, one leaf per location was dried and ground in liquid nitrogen to a fine powder for bulk $\delta^{13} \mathrm{C}$ analysis. Additionally, a second leaf from the lowest (639 $\left.\mathrm{mm} \cdot \mathrm{yr}^{-1}\right)$ and the highest $\left(1617 \mathrm{~mm} \cdot \mathrm{yr}^{-1}\right)$ precipitation locations was analyzed for potential intraleaf changes in isotopic fractionation during photosynthesis (Farquhar et al., 1989; Dawson et al., 2002; Saurer et al., 2004). These leaves were divided into two sections: the area along the midrib ("central") and the exterior portions of leaf lobes ("marginal"). These leaf sections were analyzed for isotopic heterogeneity within the leaf to account for potential heterogeneous patches in WUE.

Isotope values were measured at the Northwestern University Stable Isotope Geochemistry Laboratory on a Costech elemental analyzer (ECS 4010) connected to a Thermo Delta V Plus isotope ratio mass spectrometer (IRMS) using a Conflo IV and at the University of Illinois Chicago stable isotope laboratory with an Costech EA coupled to Finnigan Deltaplus XL IRMS. The $\delta^{13} \mathrm{C}$ values are reported relative to the standard VPDB following the equation:

$$
\delta \delta^{13} \mathrm{C}_{\text {sample }}=\left[\frac{\left({ }^{13} \mathrm{C} /{ }^{12} \mathrm{C}\right)_{\text {sample }}}{\left({ }^{13} \mathrm{C} /{ }^{12} \mathrm{C}\right)_{\text {std }}}-1\right] \cdot 1000
$$

Eq. 1

Each reported $\delta^{13} \mathrm{C}$ value is the mean of at least two replicate measurements. A cellulose standard and an internal standard created from a leaf of L. styraciflua were included with each sample run. Standard deviations of standards were within $\pm 0.1 \%$ over the course of the runs (cellulose $\mathrm{SD}=0.055, N=26$; internal standard for $L$. styraciflua $\mathrm{SD}=0.079, N=43$ ), thus a conservative estimate of instrument precision is $\pm 0.2 \%$. Statistical analysis including $t$ tests, nested ANOVAs, linear regressions, and nonlinear regressions were performed using R statistical analysis software (R Development Core Team, 2009). All reported results are mean $\pm \mathrm{SD}$.

\section{RESULTS}

Plasticity in BSE spacing within tree crown-Irradiance received by leaves varied based on cardinal orientation and peripheral, intermediate or interior canopy position due to self-shading. In leaves from open-grown $L$. styraciflua trees, mean irradiance was $983 \pm 170 \mu \mathrm{mol} \cdot \mathrm{m}^{2} \cdot \mathrm{s}^{-1}, 98 \pm 9 \mu \mathrm{mol} \cdot \mathrm{m}^{2} \cdot \mathrm{s}^{-1}$, and $39 \pm 4 \mu \mathrm{mol} \cdot \mathrm{m}^{2} \cdot \mathrm{s}^{-1}$ and BSE spacing $720 \pm 79 \mu \mathrm{m}, 959 \pm$ $159 \mu \mathrm{m}$, and $1286 \pm 263 \mu \mathrm{m}$ for peripheral, intermediate, and interior leaves, respectively (Fig. 2). A nested ANOVA found statistically significant effects of both tree $(P<0.0001)$ and canopy position $(P<0.0001$ Table 2$)$ on BSE spacing (Fig. 2$)$; high irradiance correlated with decreased BSE spacing.

In open-grown $A$. saccharum trees, mean irradiance was $864 \pm 114 \mu \mathrm{mol} \cdot \mathrm{m}^{2} \cdot \mathrm{s}^{-1}, 118 \pm 9 \mu \mathrm{mol} \cdot \mathrm{m}^{2} \cdot \mathrm{s}^{-1}$, and $21 \pm$ $1.8 \mu \mathrm{mol} \cdot \mathrm{m}^{2} \cdot \mathrm{s}^{-1}$, and BSE spacing was $231 \pm 15 \mu \mathrm{m}, 227 \pm$ $12 \mu \mathrm{m}$, and $228 \pm 13 \mu \mathrm{m}$ for peripheral, intermediate, and interior leaves, respectively. A nested ANOVA found no statistically significant differences in BSE spacing with respect to leaf canopy location $(P>0.05$, Table 2 , Fig. 2$)$. In all cases, $A$. saccharum leaves have smaller BSE spacing than leaves of L. styraciflua. Further examination of the relationship between irradiance and BSE spacing is shown in Appendix S1 (see Supplemental Data with the online version of this article). 

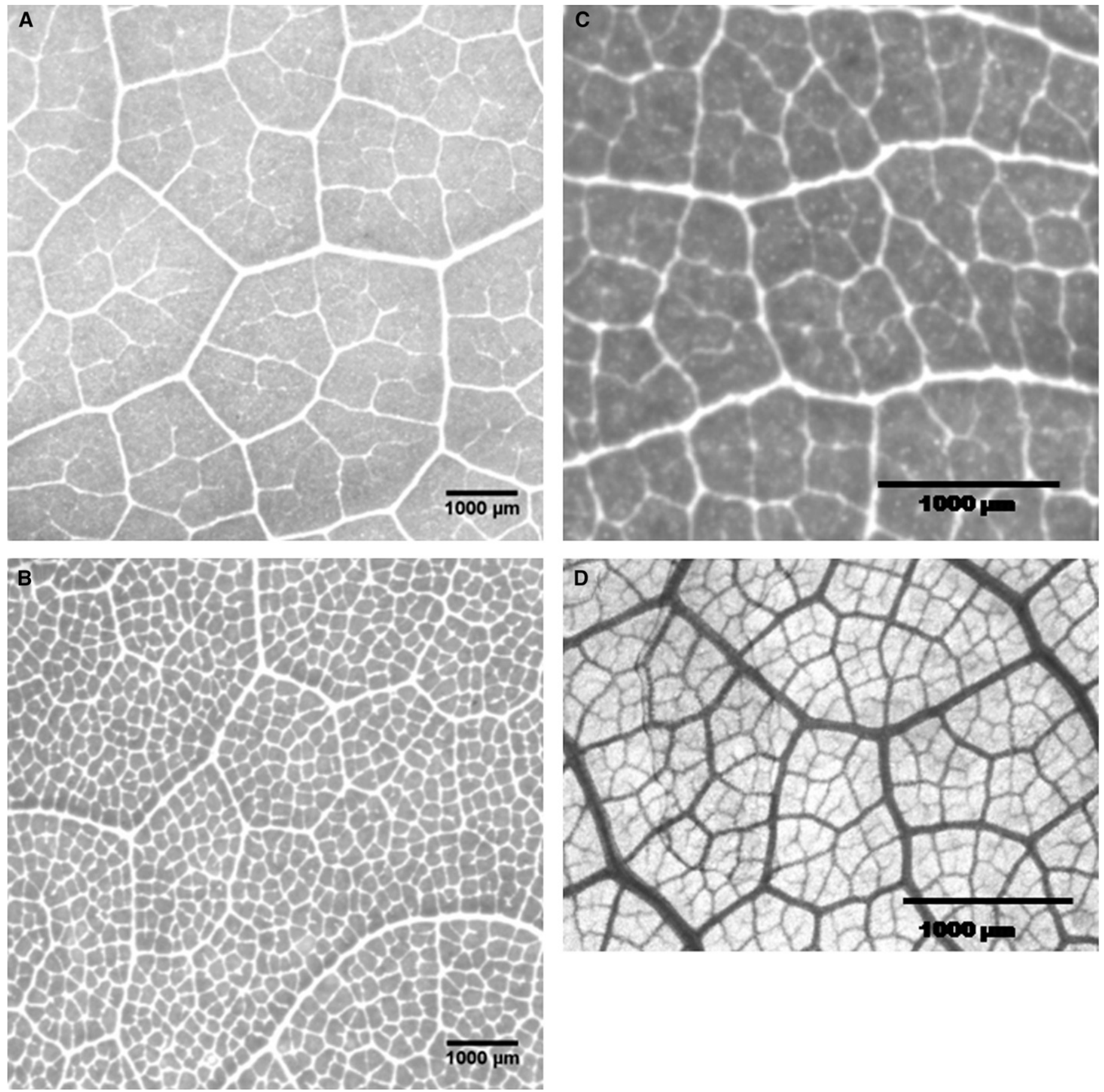

Fig. 1. Microscopy images of live leaf tissue of (A) Liquidambar styraciflua, (B) Acer saccharum, and (C) Quercus robur and cleared tissue of (D) Quercus robur. The white structures in (A-C) are bundle sheath extensions (BSEs), while the dark structures in (D) are all veins. The differences in density between image (C) and (D) demonstrate that BSEs are not present on all veins. Bar $=1000 \mu \mathrm{m}$.

Plasticity in BSE spacing along geographic precipitation gradient_-For the precipitation gradient "sun" leaves (from the southside canopy edge) measure irradiance greater than $700 \mu \mathrm{mol} \cdot \mathrm{m}^{2} \cdot \mathrm{s}^{-1}$, while "shade" leaves (from the interior crown on the north side) measured less than $60 \mu \mathrm{mol} \cdot \mathrm{m}^{2} \cdot \mathrm{s}^{-1}$. Mean annual precipitation ranged from $639 \mathrm{~mm} \cdot \mathrm{yr}^{-1}$ at the driest location to $1617 \mathrm{~mm} \cdot \mathrm{yr}^{-1}$ at the wettest location (Table 1). Bundle sheath extension spacing was positively correlated with both mean annual precipitation and year prior to sampling precipitation in L. styraciflua leaves when fit to a linear regression model: BSE in sun leaves $(y=0.36 x+427$, $\left.R^{2}=0.19, P=0.02\right)$ and shade leaves $\left(y=0.41 x+566, R^{2}=0.16\right.$, $P=0.04)$ correlated significantly with mean annual precipitation (Fig. 3A), and BSE correlated significantly with 2007 precipitation in sun leaves $\left(y=0.67 x+77.6, \mathrm{R}^{2}=0.2, P=0.02\right)$ and shade leaves (y $=0.47 x+495, \mathrm{R}^{2}=0.21, P=0.03$ ) (Fig. 3C). In contrast, BSE spacing in $A$. saccharum sun and shade leaves did not significantly correlate with mean annual precipitation or 2007 precipitation $\left(R^{2}<0.1, P>0.05\right.$ in all cases) (Fig. 3B, D). 


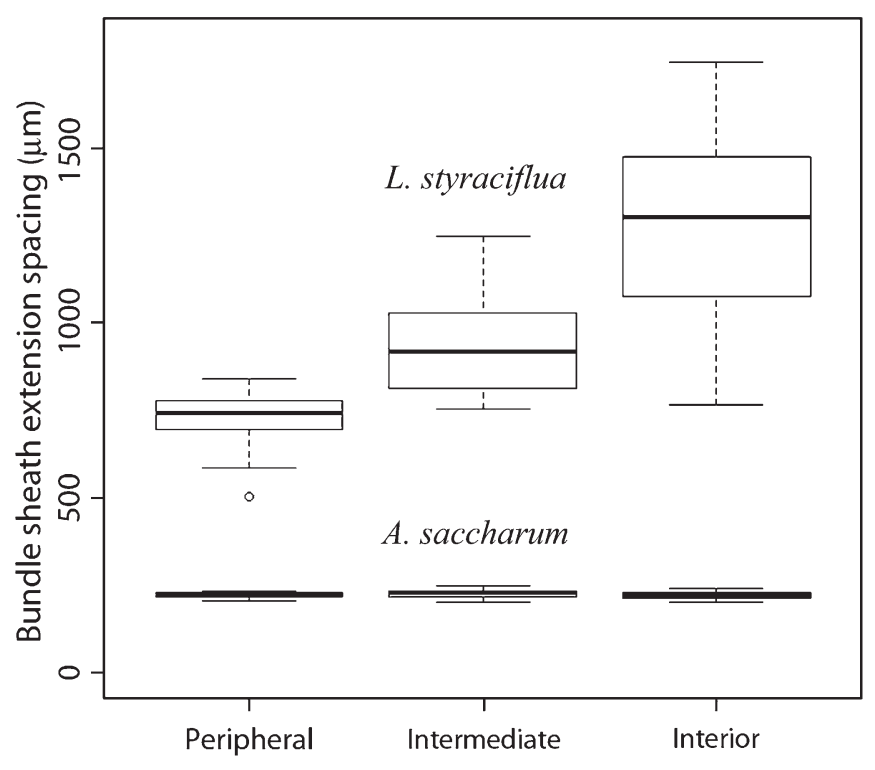

Fig. 2. Differences in bundle sheath extension (BSE) spacing between peripheral (sun) leaves, intermediate, and interior (shade) leaves in Liquidambar styraciflua (top) and Acer saccharum (bottom). For box and whisker plots, the thick bar is the median, boxes represent first and third quartiles, and whiskers represent maxima and minima. A nested ANOVA found statistically significant effects of both tree $(P<0.0001)$ and canopy position $(P<0.0001)$ on BSE spacing in $L$. styraciflua. No statistically significant differences in BSE spacing with respect to leaf canopy location were found in $A$. saccharum $(P>0.05)$.

Isotopic composition of leaves along precipitation gradient-In both $L$. styraciflua and A. saccharum, sun leaves were more enriched in ${ }^{13} \mathrm{C}$ than shade leaf counterparts (Fig. 4), and there was a significant negative correlation between bulk $\delta^{13} \mathrm{C}$ and mean annual precipitation (Fig. 4A, B) as well as the year before sampling (data not shown). Bulk leaf $\delta^{13} \mathrm{C}$ in L. styraciflua sun leaves $\left(y=-0.003 x-25.6, R^{2}=0.28, P=0.011\right)$ and shade leaves $\left(y=-0.003 x-26.9, R^{2}=0.40, P=0.002\right)$ as well as in A. saccharum sun leaves $\left(\mathrm{y}=-0.003 \mathrm{x}-25.9, \mathrm{R}^{2}=0.33\right.$, $P=0.002)$ and shade leaves $\left(y=-0.003 x-27.2, R^{2}=0.22, P=\right.$ $0.016)$ were significantly correlated with precipitation.

More positive $\delta^{13} \mathrm{C}$ values were significantly correlated with decreased BSE spacing (i.e., more heterobaric) in sun leaves of L. styraciflua (Fig. 5A $y=-0.005 x-24.74, R^{2}=0.43, P<$ $0.001)$. In contrast, more positive $\delta^{13} \mathrm{C}$ values are significantly correlated with increased BSE spacing (more homobaric) in sun leaves of A. saccharum (Fig. 5B, $y=0.029 x-34.64, R^{2}=$ $0.44, P<0.001)$. In shade leaves, neither species shows a significant correlation between $\delta^{13} \mathrm{C}$ values and BSE spacing (L. styraciflua data not shown $R^{2}=0.037, P=0.19$; A. saccharum data not shown $R^{2}=0.11, P=0.059$ ).
The sun leaves of L. styraciflua and A. saccharum showed no significant difference in bulk leaf $\delta^{13} \mathrm{C}$ values between the central and marginal portion of the leaf in either the low or high precipitation sites (Fig. 6, $P>0.05$ ). The only significant differences between the central and marginal $\delta^{13} \mathrm{C}$ values were in shade leaves, with the largest differences from low precipitation sites (Fig. 6, $t$ test: $P=0.043$ for $L$. styraciflua, $P=0.04$ for A. saccharum) and smaller, but significant difference for A. $\operatorname{saccharum}(P=0.02)$ for the high precipitation site.

Plasticity in BSE and vein spacing in growth chamber-Bundle sheath extension spacing, vein spacing, and bulk $\delta^{13} \mathrm{C}$ were analyzed from two additional canopy species from a controlled growth chamber experiment. In P. occidentalis, growth in high light chambers resulted in significantly lower BSE spacing and more positive bulk $\delta^{13} \mathrm{C}$ values but no change in vein spacing (Table 3 ). In $Q$. robur, growth in high light chambers resulted in significantly lower BSE spacing and more positive bulk $\delta^{13} \mathrm{C}$ values as well as significant changes in vein spacing, however much less change relative to the change in BSE spacing (Table 3).

\section{DISCUSSION}

Bundle sheath extension spacing in three of our four species demonstrated substantial plasticity along environmental gradients known to affect leaf gas exchange characteristics. Increased intracrown irradiance resulted in decreases in BSE spacing of ca. $200 \%$ in L. styraciflua and ca. $50 \%$ in the growth chambergrown $Q$. robur and $P$. occidentalis (Fig. 2, Table 3). Large variation was seen in BSE spacing in shade leaves of $L$. styraciflua, likely because our irradiance measurements did not accurately capture seasonal variation in irradiance, particularly in shade conditions. Additionally, decreased mean annual precipitation $\left(\sim 1600\right.$ to $\left.600 \mathrm{~mm} \cdot \mathrm{yr}^{-1}\right)$ also resulted in up to $200 \%$ decrease in BSE spacing in L. styraciflua in both high and low irradiance leaves (Fig. 3A). To our knowledge, this is the first report on BSE spacing plasticity along a regional precipitation gradient. In contrast, in leaves of A. saccharum, where BSE spacing is significantly smaller when compared to $L$. styraciflua values (Fig. 1), neither irradiance nor precipitation significantly affected BSE spacing (Figs. 2, 3B). These results contradict the previous report on this species, which did find plasticity in BSE spacing with respect to intracrown irradiance, where only one individual of this species was measured (Wylie, 1951).

The variation in BSE spacing observed in this study does not covary with changes in vein spacing. Vein spacing (Table 3) did not significantly change in $P$. occidentalis leaves grown at two irradiance levels despite a 30\% change in BSE spacing. A moderate increase in vein spacing of $10 \%$ in leaves of $Q$. robur grown at the lower irradiance was accompanied by a disproportionally

TABLE 2. Nested ANOVA results of leaf bundle sheath extension (BSE) spacing between canopy positions (peripheral, intermediate, and interior) for three individuals each of Liquidambar styraciflua and Acer saccharum.

\begin{tabular}{|c|c|c|c|c|c|c|c|c|c|c|}
\hline \multirow[b]{2}{*}{ Source of variation } & \multicolumn{5}{|c|}{ Liquidambar styraciflua } & \multicolumn{5}{|c|}{ Acer saccharum } \\
\hline & df & SS & MS & $F$ & $P$ & df & SS & MS & $F$ & $P$ \\
\hline Individual & 2 & 1097719 & 548859 & 21.3 & $<0.00001$ & 2 & 1733.4 & 866.68 & 11.2976 & $<0.00001$ \\
\hline $\begin{array}{l}\text { Canopy position } \\
\text { (individual) }\end{array}$ & 6 & 3117326 & 519554 & 20.141 & $<0.00001$ & 6 & 455.2 & 75.86 & 0.9889 & 0.4405 \\
\hline Error & 63 & 1625166 & 25796 & & & 63 & 4833.0 & 76.71 & & \\
\hline
\end{tabular}




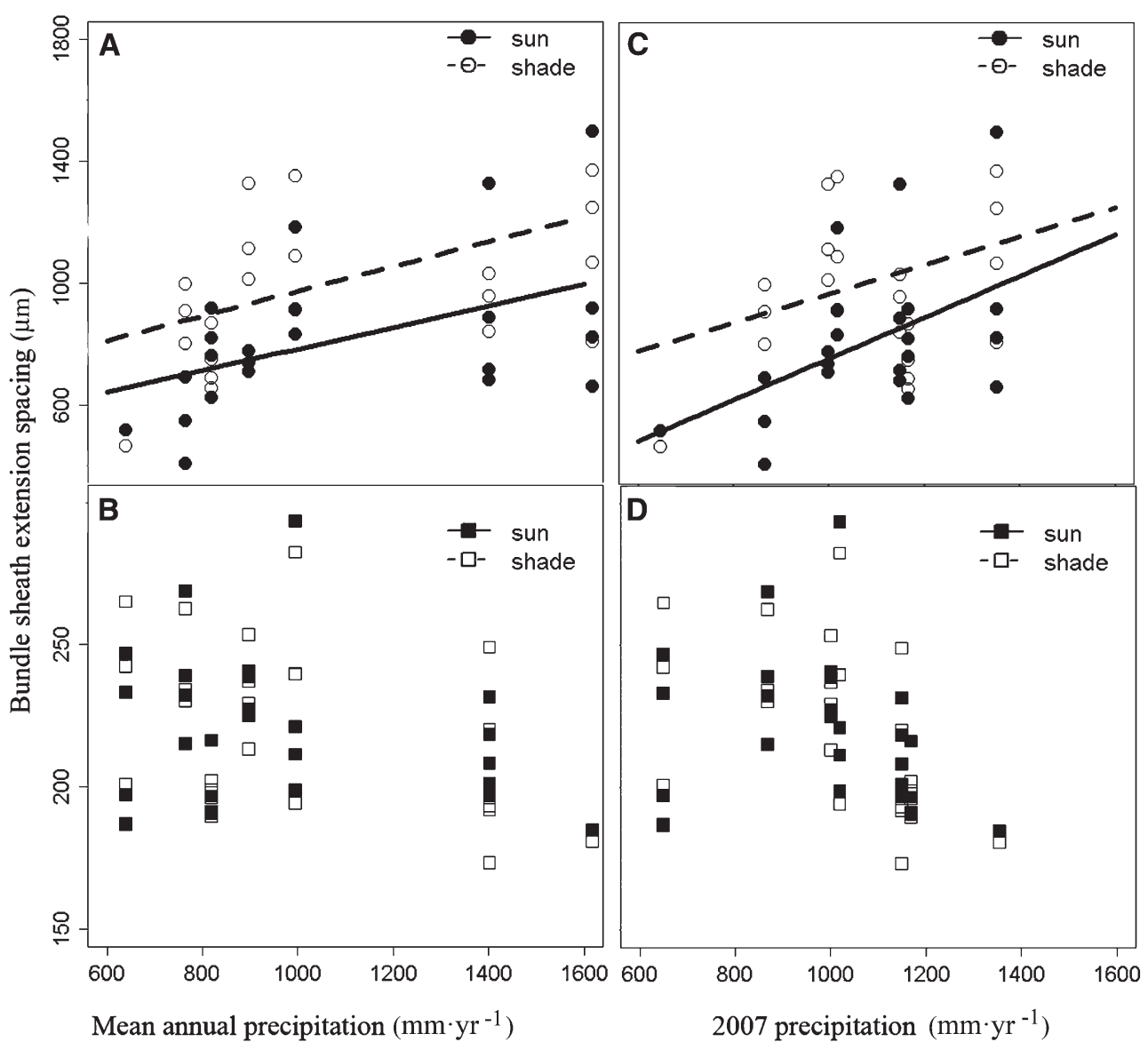

Fig. 3. Precipitation vs. bundle sheath extensions (BSE) spacing in (A, C) Liquidambar styraciflua and (B, D) Acer saccharum. Precipitation is either (A, B) mean annual precipitation (MAP) or (C, D) year prior to sampling total precipitation. Each point represents mean of six measurements from one leaf. For L. styraciflua, BSE spacing correlated significantly with MAP in sun leaves $\left(y=0.36 x+427, R^{2}=0.19, P=0.02\right)$ and shade leaves $(y=0.41 x+$ $\left.566, R^{2}=0.16, P=0.04\right)$ (Fig. 3A), and BSE correlated significantly with year before sampling precipitation in sun leaves $\left(y=0.67 x+77.6, R^{2}=0.2, P=\right.$ 0.02 ) and shade leaves $\left(y=0.47 x+495, R^{2}=0.21, P=0.03\right)$ (Fig. 3C). In contrast, BSE spacing in $A$. saccharum sun and shade leaves did not significantly correlate with any precipitation variables $\left(R^{2}<0.1, P>0.05\right.$ in all cases) (Fig. 3B, D).

larger increase in BSE spacing (30\%; Table 3). The vein-independent plasticity in BSE spacing is consistent with a functional response to the environmental drivers studied.

Leaves can modify WUE through changes in stomatal conductance (Chapin et al., 2002), mesophyll conductance (Flexas et al., 2008), or anatomical traits (Poorter and Bongers, 2006) including xylem and cell size (Fichot et al., 2009). In addition, BSEs may facilitate a quicker stomatal response to water deficiency, perhaps mitigating the reduction in WUE due to heterogeneous photosynthesis (Buckley et al., 2011, Terashima, 1992). Also, BSEs increase light capture in internal mesophyll layers and potentially enhance photosynthetic activity per leaf area (Nikolopoulos et al., 2002), indirectly improving WUE. We tested for a relationship between BSE spacing and WUE using leaf bulk $\delta^{13} \mathrm{C}$ as a proxy (Dawson et al., 2002). Although the relationship between bulk leaf $\delta^{13} \mathrm{C}$ and WUE is not necessarily linear, changes in integrated leaf water relations can be inferred from increases in bulk $\delta^{13} \mathrm{C}$ of leaves (Seibt et al., 2008). For A. saccharum, differences in regional precipitation and intracrown irradiance had no significant effect on BSE spacing, despite significant changes in $\delta^{13} \mathrm{C}$ and an expected increase in WUE over these gradients (Farquhar et al., 1982; Zimmerman and Ehleringer, 1990; Dawson et al., 2002). The observed changes in bulk leaf $\delta^{13} \mathrm{C}$ values of $A$. saccharum (Fig. 5B) have been previously seen in response to changes in water availability (Garten and Taylor, 1992) and indicate that traits other than BSE spacing are affecting WUE. The limited plasticity of BSE spacing seen in A. saccharum along environmental gradients known to affect WUE does not support the notion that BSEs are required to improve WUE.

There was substantial variation in BSE spacing with respect to irradiance and/or precipitation in the other three species studied. Along the precipitation gradient, bulk leaf $\delta^{13} \mathrm{C}$ values were significantly inversely correlated with BSE spacing in sun leaves of $L$. styraciflua (Fig. 5A). The $3 \%$ increase in $\delta^{13} \mathrm{C}$ corresponded to a $200 \%$ decrease in BSE spacing. A similar inverse correlation is also seen in leaves of the chamber-grown $Q$. robur and $P$. occidentalis seedlings where only irradiance was varied (Table 3). Additionally, the intercrown analysis of L. styraciflua showed a significant decrease in BSE spacing with increased irradiance (Fig. 2), which has also been shown to correlate with changes in $\delta^{13} \mathrm{C}$ and perhaps WUE in other studies (Zimmerman and Ehleringer, 1990; Le Roux et al., 2001). Together, these results are consistent with improved WUE with higher density of BSE in L. styraciflua, Q. robur, and $P$. occidentalis. 


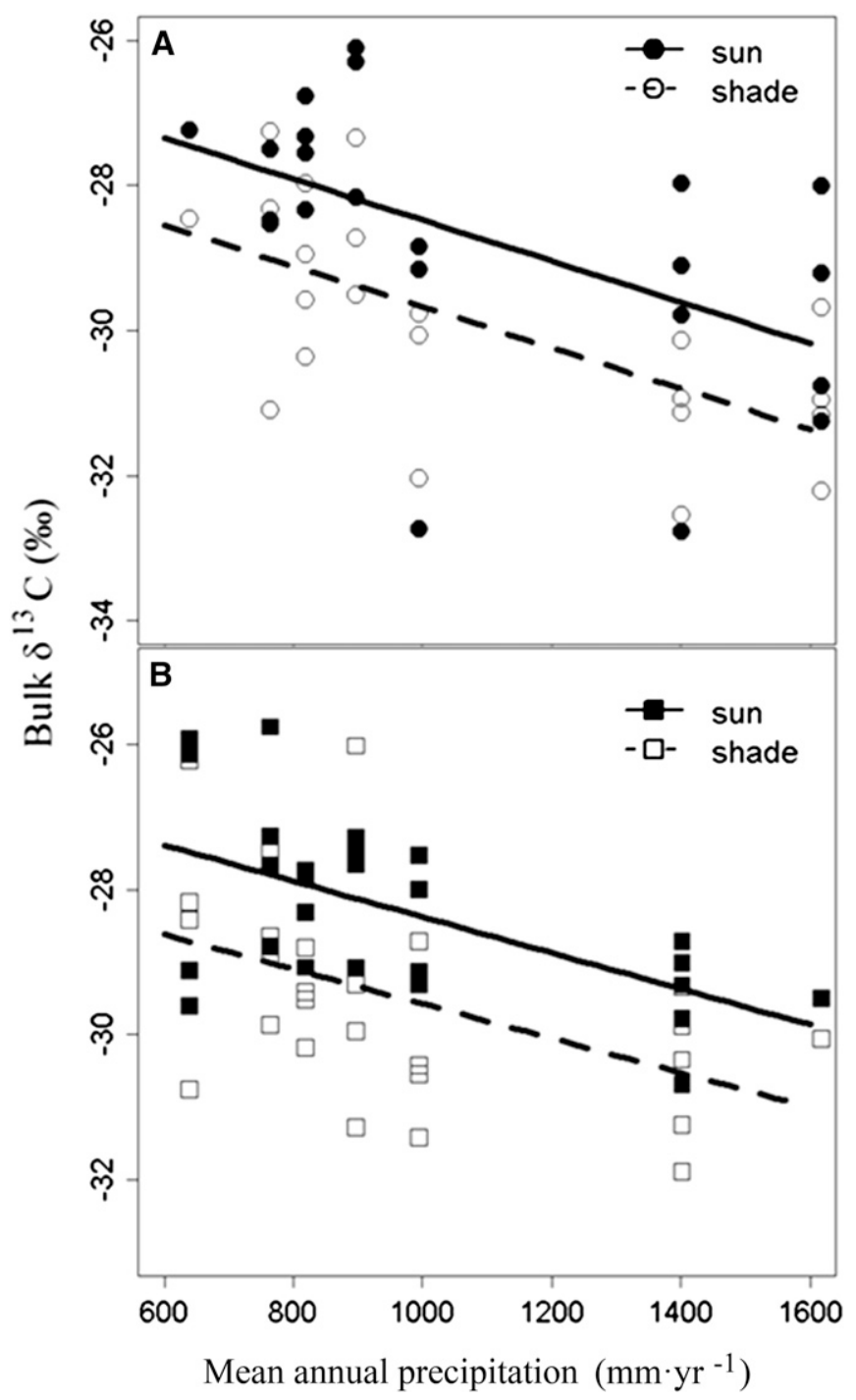

Fig. 4. Mean annual precipitation vs. bulk $\delta^{13} \mathrm{C}$ in (A) Liquidambar styraciflua and (B) Acer saccharum. Each point represents the mean of two measurements from one leaf. Bulk leaf $\delta^{13} \mathrm{C}$ significantly correlated with precipitation in all cases: $L$. styraciflua sun leaves $\left(y=-0.003 x-25.6, R^{2}=\right.$ $0.28, P=0.011), L$. styraciflua shade leaves $\left(y=-0.003 \times-26.9, R^{2}=0.40\right.$, $P=0.002), A$. saccharum sun leaves $\left(y=-0.003 x-25.9, R^{2}=0.33, P=\right.$ $0.002)$, and $A$. saccharum shade leaves $\left(y=-0.003 x-27.2, R^{2}=0.22, P=\right.$ 0.016).

Caution should be employed in interpreting the relationship between leaf carbon isotopic composition and WUE in plant leaves (Seibt et al., 2008). Changes in mesophyll conductance for $\mathrm{CO}_{2}$ (Farquhar et al., 1982; Flexas et al., 2008; Seibt et al., 2008; Terashima et al., 2011) and to a lesser extent photosynthetic uptake of plant respired $\mathrm{CO}_{2}$ (Damesin et al., 2005; Moore et al., 2008; Teskey et al., 2008) can induce changes in leaf $\delta^{13} \mathrm{C}$ that are not associated with changes in WUE because photosynthesis responds to the $\mathrm{CO}_{2}$ concentration inside mesophyll cells rather than intercellular $\mathrm{CO}_{2}$ concentration $\left(C_{\mathrm{i}}\right)$. Therefore, the relationship between WUE and the leaf carbon isotopic composition can become nonlinear (Seibt et al., 2008). Additionally, potential variations in the ratio of evaporation to stomatal conductance between sites may complicate the interpretation of

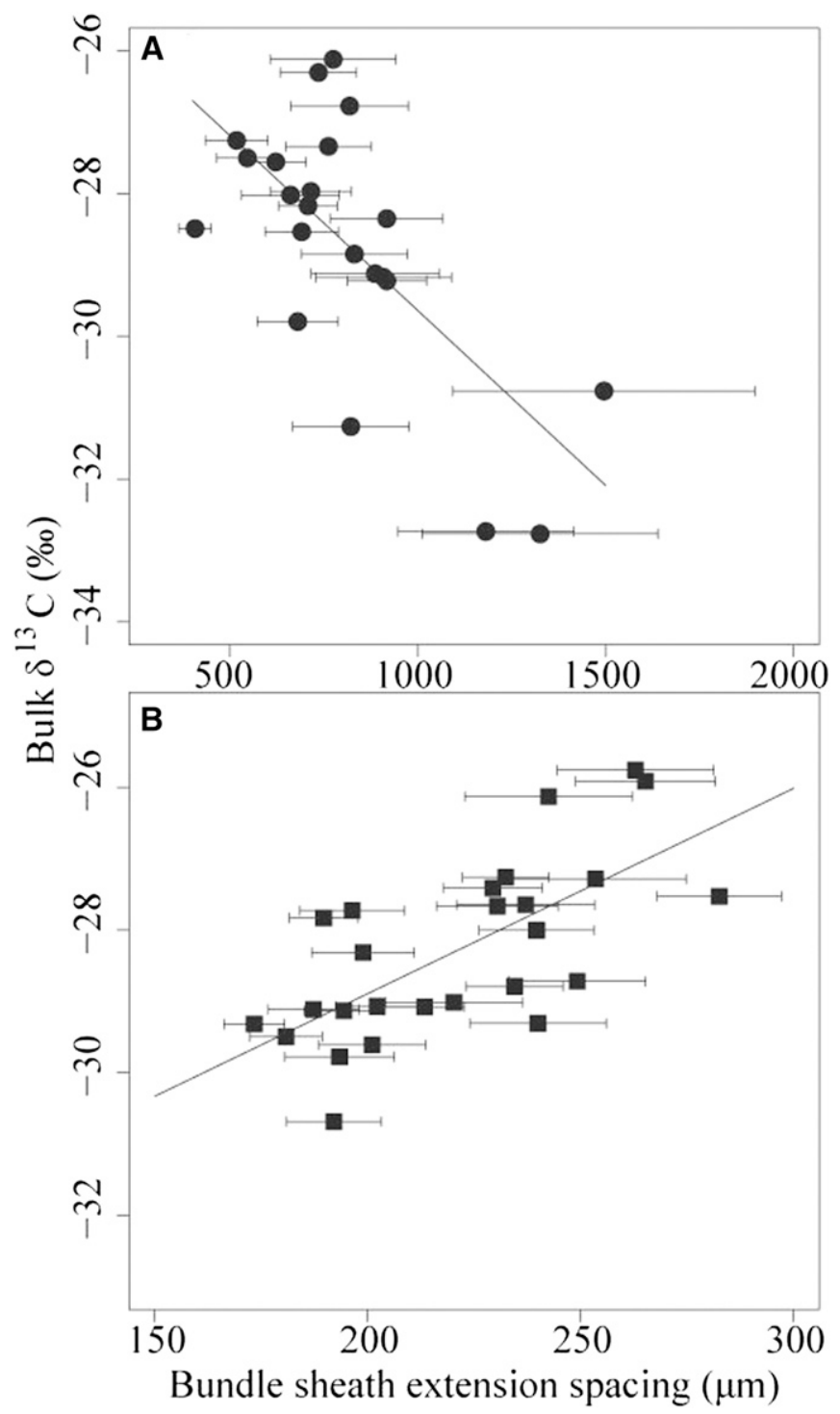

Fig. 5. Bundle sheath extension (BSE) spacing vs. bulk $\delta^{13} \mathrm{C}$ in sun leaves of (A) Liquidambar styraciflua and (B) Acer saccharum. Note different $x$-axis scales for (A) and (B). Error bars for BSE spacing are one SD. Each point represents mean of measurements from one leaf $(N=6$ for BSE spacing, $N=2$ for bulk $\delta^{13} \mathrm{C}$ ). More positive $\delta^{13} \mathrm{C}$ values are significantly correlated with decreased BSE spacing (i.e., more heterobaric) in sun leaves of L. styraciflua (Fig. 5A, $y=-0.005 x-24.74, R^{2}=0.43, P<$ $0.001)$. More positive $\delta^{13} \mathrm{C}$ values are significantly correlated with increased BSE spacing (more homobaric) in sun leaves of A. saccharum (Fig. 5B, $y=0.029 x-34.64, R^{2}=0.44, P<0.001$ ).

the relationship between $\delta^{13} \mathrm{C}$ and WUE. Although changes in WUE will lead to changes in bulk leaf $\delta^{13} \mathrm{C}$, BSE presence in heterobaric leaves potentially affects the lateral conductance to both $\mathrm{CO}_{2}$ and $\mathrm{H}_{2} \mathrm{O}$, which could result in a nonhomogenous carbon isotope fractionation of photosynthesis across the leaf.

We examined the effects of compartmentalization on intraleaf carbon isotopic composition by comparing bulk leaf $\delta^{13} \mathrm{C}$ at the center and the margin of our heterobaric leaves. If compartments of heterobaric leaves have distinct gas exchange properties (particularly with respect to patchiness in stomatal conductance), then the ${ }^{13} \mathrm{C}$ isotopic composition of a single leaf 


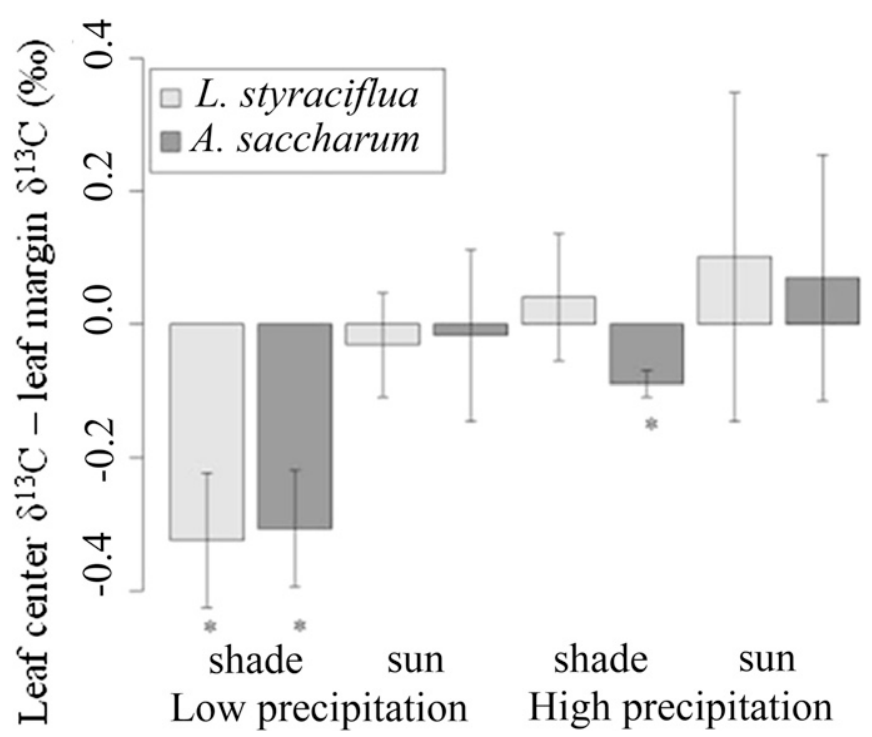

Fig. 6. The mean difference between $\delta^{13} \mathrm{C}$ values of the leaf center (surrounding the midrib) and the leaf margin (edges of the lobes) for Liquidambar styraciflua and Acer saccharum grown in the extreme low (639 $\left.\mathrm{mm} \cdot \mathrm{yr}^{-1}\right)$ and high $\left(1617 \mathrm{~mm} \cdot \mathrm{yr}^{-1}\right)$ precipitation environments. Each bar represents mean of three leaves. Error bars are one standard deviation. Asterisks indicate a significant $(P<0.05)$ difference from 0 .

should also be heterogeneous. This heterogeneity should be particularly pronounced when compartment size is relatively small and also when water demand is high as in sun leaves under low precipitation. However, our results show that in both species only shade leaves demonstrate a significantly depleted isotopic composition in the center of the leaf compared to the margin of the leaf (Fig. 6). Isotopic depletion in the center of shade leaves suggest higher $C_{\mathrm{i}}$ relative to the leaf margin (and thus a potential decreased WUE), despite proximity to primary veins and likely improved access to water. The isotopic depletion in the center of heterobaric shade leaves is contrary to expected results from compartmentalization and stomatal patchiness. Thus, other potential mechanisms likely impact the isotopic composition in these leaves, including the photosynthetic recycling of respired $\mathrm{CO}_{2}$.

TABLE 3. Bundle sheath extension spacing, vein spacing, and $\delta^{13} \mathrm{C}$ values from growth chamber experiment with Platanus occidentalis and Quercus robur.

\begin{tabular}{|c|c|c|c|c|}
\hline \multirow[b]{2}{*}{ Species } & \multirow[b]{2}{*}{ Light } & $\delta^{13} \mathrm{C}(\% o)$ & \multirow{2}{*}{$\frac{\text { BSE spacing }(\mu \mathrm{m})}{\text { Mean } \pm \mathrm{SD}}$} & \multirow{2}{*}{$\frac{\text { Vein spacing }(\mu \mathrm{m})}{\text { Mean } \pm \mathrm{SD}}$} \\
\hline & & Mean \pm SD & & \\
\hline \multirow[t]{2}{*}{ P. occidentalis } & High & $-28.5 \pm 2.1 *$ & $273 \pm 34 *$ & $194 \pm$ \\
\hline & Low & $-30.9 \pm 1.3$ & $386 \pm 48$ & $194 \pm 39$ \\
\hline \multirow[t]{2}{*}{ Q. robur } & High & $-26.9 \pm 0.77^{*}$ & $261 \pm 31 *$ & $164 \pm 23^{*}$ \\
\hline & Low & $-35.4 \pm 1.4$ & $366 \pm 34$ & $181 \pm 18$ \\
\hline
\end{tabular}

Notes: Light refers to treatment in leaf chamber: high light (200-300 $\left.\mu \mathrm{mol} \cdot \mathrm{m}^{2} \cdot \mathrm{s}^{-1}\right)$ or low light $\left(20-40 \mu \mathrm{mol} \cdot \mathrm{m}^{2} \cdot \mathrm{s}^{-1}\right)$. Each mean and standard deviation (SD) reported is based on results from $N=4$ leaves per chamber for BSE spacing and $N=5$ leaves per chamber for vein spacing. Statistical analysis was performed by $t$ test; asterisk denotes significant differences in a trait between high and low treatments for a species $(P \leq 0.05)$. Carbon isotope ratio of $\mathrm{CO}_{2}$ in the chambers was unknown but was likely similar in the two chambers as the $\mathrm{CO}_{2}$ was sourced from outside air in both chambers.
If respired $\mathrm{CO}_{2}$ were to significantly contribute to photosynthesis in heterobaric leaves (see Teskey et al., 2008), the carbon of the leaf tissue near main veins would be depleted in ${ }^{13} \mathrm{C}$ relative to that of outer leaf portions where atmospheric $\mathrm{CO}_{2}$ should be the major source for photosynthesis. The difference in isotopic composition between central and marginal parts of the leaf with respect to the recycling of xylem transported respired $\mathrm{CO}_{2}$ should be more apparent when rates of photosynthesis are low (e.g., shade leaves, dry sites), as is the case for shade leaves of A. saccharum grown in both wet and dry sites and shade leaves of L. styraciflua grown at dry sites (Fig. 6). Considerable refixation of xylem respired $\mathrm{CO}_{2}$ has been previously shown experimentally in leaves of P. occidentalis (Teskey et al., 2008), and our results are consistent with this possibility. Therefore BSE spacing may play different roles under different irradiance and precipitation regimes, where narrower BSE spacing can indirectly aid WUE at high irradiance under low precipitation but can have other functions such as aiding in recycling respired $\mathrm{CO}_{2}$ at low irradiance.

Clear trends were found in the response of BSE spacing to irradiance and precipitation in $L$. styraciflua, $Q$. robur, and P. occidentalis. However, in leaves of A. saccharum, BSE spacing was not found to be plastic along these gradients. It is noteworthy that the three species with significant BSE plasticity are canopy shade-intolerant species, while the lone species lacking BSE plasticity is an understory, shade-intolerant species (White, 1983). Differences in canopy position have recently been shown to influence presence of BSE in species, most significantly in a lowland tropical rainforest in Malaysia, where a majority of canopy species were heterobaric, while a majority of understory species were homobaric (Kenzo et al., 2007). No such ecological difference has been examined in temperate forests, but our results are suggestive that similar patterns may emerge with additional studies.

Other physiologically relevant anatomical features, in addition to plasticity in BSE spacing shown in this study, distinguish the two main species used in this research. For example, L. styraciflua has been shown to decrease leaf thickness in response to decreased irradiance (Kjelgren and Clark, 1992), whereas leaves of $A$. saccharum do not change leaf thickness in response to irradiance or precipitation (Niinemets, 2001; Sack et al., 2003). Changes in both leaf thickness and BSE spacing in the canopy species relate to compartment volume, which affects spatial heterogeneity in a leaf, ultimately impacting water relations (Terashima, 1992). In A. saccharum, a general lack of plasticity in traits affecting compartment volume (BSE spacing and leaf thickness) with respect to irradiance and precipitation may point to other physiological function for BSEs such as prevention of disease spread or mechanical support (Lawson and Morison, 2006). Future work examining BSE responses to environmental factors in additional species is needed to confirm this potential link between life history and BSE plasticity and function.

In conclusion, results presented here demonstrate for the first time that BSE spacing is a plastic trait in some species with respect to irradiance and precipitation, variables known to affect plant WUE. A lack of consistency in BSE plasticity across species does not support a strong direct role for BSE in improving WUE. Despite the importance of leaf venation patterns in leaf function (Brodribb et al., 2010), the function(s) and evolutionary advantage of BSEs surrounding veins remains unclear. Our results suggest future studies should examine functions such as mechanical support or prevention of disease spread for BSEs. 
Additionally, a potential contrast in BSE plasticity between canopy and shade-tolerant species with respect to BSE spacing expression deserves further investigation.

\section{LITERATURE CITED}

Blonder, B., C. Violle, L. P. Bentley, and B. J. Enquist. 2011. Venation networks and the origin of the leaf economics spectrum. Ecology Letters 14: 91-100.

Brodribb, T. J., AND T. S. FeILD. 2010. Leaf hydraulic evolution led a surge in leaf photosynthetic capacity during early angiosperm diversification. Ecology Letters 13: 175-183.

Brodribb, T. J., T. S. Feild, and L. Sack. 2010. Viewing leaf structure and evolution from a hydraulic perspective. Functional Plant Biology 37: 488-498

Buckley, T. N., L. SACK, and M. E. Gilbert. 2011. The role of bundle sheath extensions and life form in stomatal responses to leaf water status. Plant Physiology 156: 962-973.

Chapin, F. S. III, P. A. Matson, And H. A. Mooney. 2002. Principles of terrestrial ecosystem ecology. Springer-Verlag, New York, New York, USA.

Damesin, C., C. Barbaroux, D. Berveiller, C. Lelarge, M. Chaves, C. Maguas, R. Maia, and J. Y. Pontalller. 2005. The carbon isotope composition of $\mathrm{CO}_{2}$ respired by trunks: Comparison of four sampling methods. Rapid Communications in Mass Spectrometry 19: 369-374.

Dawson, T., S. Mambelli, A. Plamboeck, P. Templer, and K. Tu. 2002. Stable isotopes in plant ecology. Annual Review of Ecology and Systematics 33: 507-559.

Ellis, B., D. C. Douglas, L. J. Hickey, K. R. Johnson, J. D. Mitchell, P. WiLf, AND S. L. Wing. 2009. Manual of leaf architecture. Cornell University Press, Ithaca, New York, USA. 190 pp.

EsaU, K. 1953. Plant anatomy. John Wiley, New York, New York, USA.

Farquhar, G. D., J. R. Ehleringer, and K. T. Hubick. 1989. Carbon isotope discrimination and photosynthesis. Annual Review of Plant Physiology and Plant Molecular Biology 40: 503-537.

Farquhar, G. D., M. H. O'Leary, and J. A. Berry. 1982. On the relationship between carbon isotope discrimination and the intercellular carbon dioxide concentration in leaves. Australian Journal of Plant Physiology 9: 121-137.

Fichot, R., F. Laurans, R. Monclus, A. Moreau, G. Pilate, and F. BRIGNOLAS. 2009. Xylem anatomy correlates with gas exchange, water-use efficiency and growth performance under contrasting water regimes: Evidence from Populus deltoides $\times$ Populus nigra hybrids. Tree Physiology 29: 1537-1549.

Flexas, J., M. Ribas-Carbó, A. Diaz-Espejo, J. Galmés, and H. Medrano. 2008. Mesophyll conductance to $\mathrm{CO} 2$ : Current knowledge and future prospects. Plant, Cell \& Environment 31: 602-612.

Garten, C. T., and G. E. TAYloR JR. 1992. Foliar $\delta^{13} \mathrm{C}$ within a temperate deciduous forest: Spatial, temporal, and species sources of variation. Oecologia 90: 1-7.

Gonzalez-Meler, M. A., And L. Taneva. 2005. Integrated effects of atmospheric $\mathrm{CO}_{2}$ concentration on plant and ecosystem respiration. In H. Lambers and M. Ribas-Carbo[(eds.], Plant respiration, 211-259. Kluwer, Dordrecht, Netherlands.

Kenzo, T., T. Ichie, Y. Watanabe, and T. Hiromi. 2007. Ecological distribution of homobaric and heterobaric leaves in tree species of Malaysian lowland tropical rainforest. American Journal of Botany 94: 764-775.

Kuelgren, R. K., and J. R. Clark. 1992. Photosynthesis and leaf morphology of Liquidambar styraciflua L. under variable urban radiant energy conditions. International Journal of Biometeorology 36: $165-171$.

Lavorel, S., K. Grigulis, P. Lamarque, M. Colace, D. Garden, J. Girel, G. Pillet, and R. Douzet. 2011. Using plant functional traits to understand the landscape distribution of multiple ecosystem services. Journal of Ecology 99: 135-147.

Lawson, T., AND J. Morison. 2006. Visualising patterns of $\mathrm{CO}_{2}$ diffusion in leaves. New Phytologist 169: 641-643.

LEEGOOD, R. C. 2008. Roles of the bundle sheath cells in leaves of $\mathrm{C}_{3}$ plants. Journal of Experimental Botany 59: 1663-1673.
Le Roux, X., T. Bariac, H. Sinoquet, B. Genty, C. Piel, A. Mariotti, C. GIRARDIN, AND P. RICHARD. 2001. Spatial distribution of leaf wateruse efficiency and carbon isotope discrimination within an isolated tree crown. Plant, Cell \& Environment 24: 1021-1023.

Lockheart, M. J., P. F. VAn Bergen, AND R. P. Evershed. 1997. V Variations in the stable carbon isotope compositions of individual lipids from the leaves of modern angiosperms: Implications for the study of higher land plant-derived sedimentary organic matter. Organic Geochemistry 26: 137-153.

Moorcroft, P. R., G. C. Hurtt, and S. W. Pacala. 2001. A method for scaling vegetation dynamics: The ecosystem demography model (ED). Ecological Monographs 71: 557-585.

Moore, D. J. P., M. A. Gonzalez-Meler, L. Taneva, J. S. Pippen, H. S. Kim, and E. H. DeLucia. 2008. The effect of carbon dioxide enrichment on apparent stem respiration from Pinus taeda L. is confounded by high levels of soil carbon dioxide. Oecologia 158: 1-10.

Morison, J., AND T. Lawson. 2007. Does lateral gas diffusion in leaves matter? Plant, Cell \& Environment 30: 1072-1085.

Morison, J., T. Lawson, AND G. Cornic. 2007. Lateral $\mathrm{CO}_{2}$ diffusion inside dicotyledonous leaves can be substantial: Quantification in different light intensities. Plant Physiology 145: 680-690.

NinEMETS, U. 2001. Global-scale climatic controls of leaf dray mass per area, density, and thickness in trees and shrubs. Ecology 82: 453-469.

NikLAS, K. J. 1997. Adaptive walks through fitness landscapes for early vascular land plants. American Journal of Botany 84: 16-25.

Nikolopoulos, D., G. Liakopoulos, I. Drossopoulus, and G. Karabourniotis. 2002. The relationship between anatomy and photosynthetic performance of heterobaric leaves. Plant Physiology 129: 235-243.

Pieruschka, R., A. Chavarria-Krauser, K. Cloos, H. Scharr, U. SCHURR, AND S. JAHNKE. 2008. Photosynthesis can be enhanced by lateral $\mathrm{CO}_{2}$ diffusion inside leaves over distances of several millimeters. New Phytologist 178: 335-347.

PieruschKa, R., U. Schurr, and S. JahnKe. 2005. Lateral gas diffusion inside leaves. Journal of Experimental Botany 56: 857-864.

Pieruschka, R., U. Schurr, M. Jensen, W. Wolff, and S. Jahnke. 2006. Lateral diffusion of $\mathrm{CO}_{2}$ from shaded to illuminated leaf parts affects photosynthesis inside homobaric leaves. New Phytologist 169: 779-788.

PoORTER, L., AND F. Bongers. 2006. Leaf traits are good predictors of plant performance across 53 rain forest species. Ecology 87: 1733-1743.

PRISM Climate Group. 2009. PRISM Climate Group, Oregon State University, website http://www.prismclimate.org, created 4 Feb 2004, [accessed 1 April 2009].

R Development Core Team. 2009. R: A language and environment for statistical computing. R Foundation for Statistical Computing, Vienna, Austria. ISBN 3-900051-07-0, website http://www.R-project. org.

RASBAND, W. S. 1997-2008. ImageJ [computer program]. U. S. National Institutes of Health, Bethesda, Maryland, USA, website http://rsb. info.nih.gov/ij/.

Roth-Nebelsick, A., D. Uhl, V. Mosbrugger, and H. Kerp. 2001. Evolution and function of leaf venation architecture: A review. Annals of Botany 87: 553-566.

Sack, L., P. D. Cowan, N. Jaikumar, and N. M. Holbrook. 2003. The 'hydrology' of leaves: Co-ordination of structure and function in temperate woody species. Plant, Cell \& Environment 26: $1343-1356$.

Saurer, M., R. Siegwolf, and F. Schweingruber. 2004. Carbon isotope discrimination indicates improving water-use efficiency of trees in northern Eurasia over the last 100 years. Global Change Biology 10: 2109-2120.

Seibt, U., A. Rajabi, H. Griffiths, and J. Berry. 2008. Carbon isotopes and water use efficiency: Sense and sensitivity. Oecologia 155: 441-454.

Terashima, I. 1992. Anatomy of non-uniform leaf photosynthesis. Photosynthesis Research 31: 195-212. 
Terashima, I., Y. T. Hanba, D. Tholen, and Ü. NiIemets. 2011. Leaf functional anatomy in relation to photosynthesis. Plant Physiology 155: 108-116.

Teskey, R. O., A. Saveyn, K. Steppe, and M. A. McGuire. 2008. Origin, fate and significance of $\mathrm{CO}_{2}$ in tree stems. New Phytologist 177: 17-32.

Uhl, D., and V. Mosbrugger. 1999. Leaf venation density as a climate and environmental proxy: A critical review and new data. Palaeogeography, Palaeoclimatology, Palaeoecology 149: 15-26.

White, P. S. 1983. Corner's rules in eastern deciduous trees: Allometry and its implications for the adaptive architecture of trees. Bulletin of the Torrey Botanical Club 110: 203-212.
WyLIE, R. B. 1951. Principles of foliar organization shown by sun-shade leaves from ten species of deciduous dicotyledonous trees. American Journal of Botany 38: 355-361.

Wylie, R. B. 1952. The bundle sheath extension in leaves of dicotyledons. American Journal of Botany 39: 645-651.

Zimmerman, J. K., AND J. R. Ehleringer. 1990. Carbon isotope ratios are correlated with irradiance levels in the Panamanian orchid Catasetum viridiflavum. Oecologia 83: 247-249.

ZwIENIECKI, M. A., C. K. BoyCE, AND N. M. Holbrook. 2004. Hydraulic limitations imposed by crown placement determine final size and shape of Quercus rubra L. leaves. Plant, Cell \& Environment 27: 357-365. 